\title{
Meteorological Parameters and Daytime Maximum Electricity Demand in Makassar, Indonesia
}

\author{
Yusri Syam Akil, Syafaruddin, Tajuddin Waris, and Imran Taufik
}

\begin{abstract}
As in the peak period electricity demand is high, providing a demand model to analyze load condition particularly during maximum demand period is important in relation to keep continuity service to connected consumers. In this research, effect of meteorological variables and holidays particularly on daytime maximum demand period for a total load for five different demand areas in Makassar - Indonesia are observed by developed demand models based on regression method using hourly data. We firstly observe characteristics of demand for whole period through $W P E D_{m}$ model as a basis analysis. Next, we explore typical characteristic when daytime maximum demand period by creating $D M D_{m}$ model. In order to find better model, some options for each model are composed and assessed by standard statistical tests. From results, it is confirmed the composed models are well validated. Load drivers and their effect on the observed demand periods are found unique.
\end{abstract}

Index Terms-Demand characteristic, daytime maximum demand, meteorological variables, electricity demand model, Makassar.

\section{INTRODUCTION}

In relation to operation of power systems, it is commonly known that concern of a power utility is mainly given during maximum demand period or peak hours as electricity demand is high in this period. This caused, under high demand period, a number of risks such as frequency oscillation or voltage violation [1] can highly occur in the certain systems which can influence the continuity service to connected consumers. With regards to this, knowing characteristics of peak demand is valuable information for utilities as it can be utilized for purpose managing of power system operation. However, a demand model is usually needed to perform demand analyses Regarding data required for model, it is well known the availability and accessibility of data is an important aspect since they may not available and / or not open for public. A number of efforts to dealing with maximum demand more effective have been done in different places [1]-[5].

As an extended version of [6], this present study has focus to investigate demand characteristics mainly during maximum demand period for Indonesia context. Meteorological parameters and holidays are considered to

Manuscript received October 9, 2014; revised March 29, 2015. This work is supported by Institute for Research and Community Services (LP2M) Hasanuddin University.

Y. S. Akil, Syafaruddin, and T. Waris are with the Electrical Engineering Department, Hasanuddin University, Makassar 90245 Indonesia, Indonesia (e-mail: yusakil@unhas.ac.id, yusakil@yahoo.com, syafaruddin@ unhas.ac.id, tajuddin@unhas.ac.id).

I. Taufik is with the STMIK Handayani Makassar, Indonesia (e-mail: imran_taufik@yahoo.co.id). explain pattern of demand in the observed period. As a basis analysis, an initial demand model $\left(\mathrm{WPED}_{\mathrm{m}}\right.$ model) which expressed whole period of demand are firstly composed and analyzed. Next, investigation of typical load characteristics particularly during daytime maximum demand period is done. From the previous work, one author has analyzed the peak electricity demand in Japan [7], [8]. It is hoped, this current research can contribute in managing power system under tropical condition mainly during maximum demand periods more effective, and further may help in determining proper needed actions to keep service to electric consumers.

\section{DATA SET}

In this study, analyzed demand data obtained from PT. PLN (Persero) APD Makassar are hourly total load data for five different demand areas in Makassar, Indonesia from 14 September 2013 to 13 November 2013 (1464 hourly observations). These data are typical total demand for studied areas as disaggregated data for each sector (such as residential, commercial) and data for other months are not completely available mainly for explanation variables. To explain demand characteristic during maximum period, meteorological and holidays variables are considered in model. Meteorological parameters namely temperature $T$ $\left({ }^{\circ} \mathrm{C}\right)$, relative humidity $H M D(\%)$, and wind speed $W S D$ $(\mathrm{m} / \mathrm{sec})$ are taken from National Institute of Aeronautics and Space of Indonesia (LAPAN). Meanwhile holidays' data (Saturday, Monday, and national holidays in Indonesia) are collected from calendar.

\section{BASIC DATA ANALYSIS AND PROPOSED MODEL}

\section{A. Basic Data Analysis}

As preliminary investigation to characteristic of demand, variation of daily load, and natural values of temperature and relative humidity for one week (14 to 20 September 2013) are presented in Fig. 1. In Fig. 1(a), electricity demand has daily fluctuation, and it tends to low in holidays rather than in non-holidays. Demand have daily maximum demand periods which occur at daytime and in evening. Besides, daily demand particularly in daytime maximum demand hours tends to follow variation of meteorological variables mainly for temperature as seen in Fig. 1(a) and Fig. 1(b). Particularly for temperature, variation of its values each month between Year 2010 to Year 2012 in Makassar is presented in Fig. 2. In general, the temperature values are relatively higher in September, October, and November compared to other months as seen in Fig. 2. 


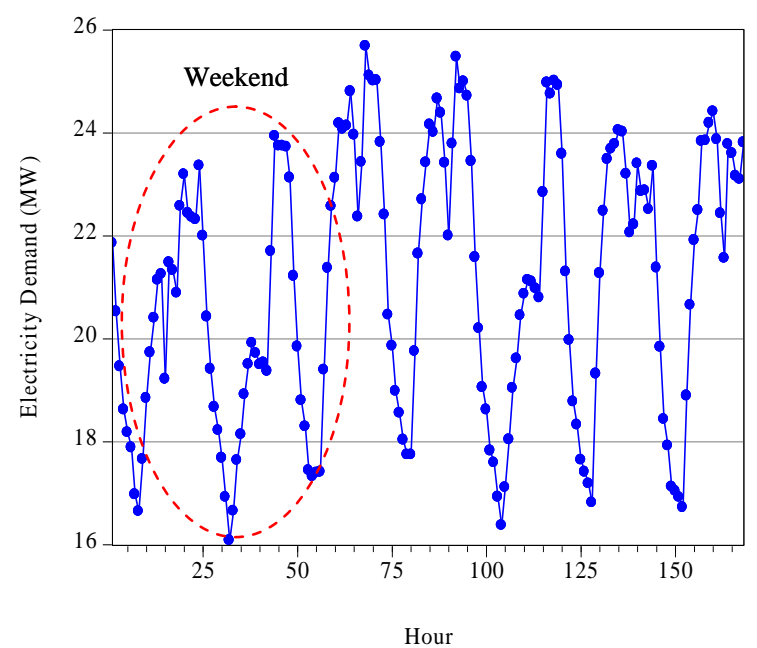

(a)

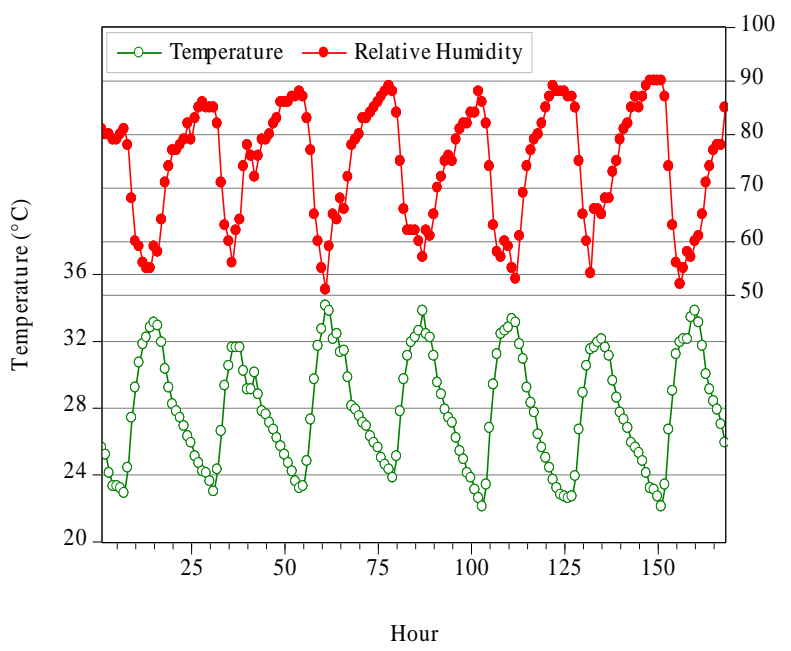

(b)

Fig. 1. Samples of daily load curve, temperature and humidity values in Makassar between14 (Saturday) and 20 (Friday) September 2013

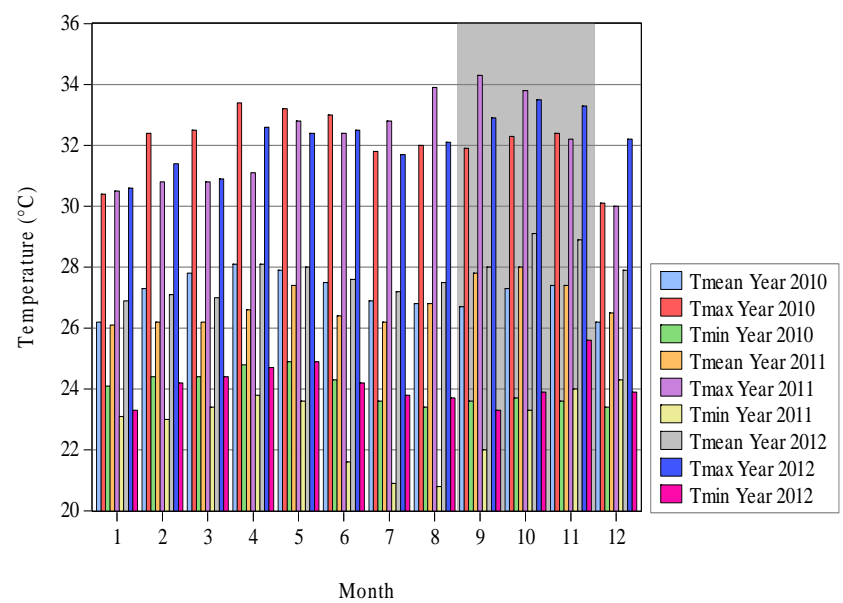

Fig. 2. Monthly temperature values in Makassar city for year 2010 to year 2012 [9].

To reveal more characteristics of demand, regression based demand model are composed as a tool analysis as described in next section. In this study, utilization of regression method is enough effective as obtained regression results give specific information about relationship between demand and each explanation variable in related model which is not difficult to explain and also to construct proposed model.

\section{B. Proposed Model}

In this case, we firstly observe characteristics of demand for whole period as a basis analysis through $W P E D_{m}$ model. Next, typical daytime maximum demand characteristic is identified by using $D M D_{m}$ model. Both of the models are briefly described below.

\section{1) WPED $D_{m}$ model}

Here, whole period of demand data are used in model to reveal typical characteristic of demand in general. Five explanation variables are considered in model namely $C D D$, $C D D(-1)$, humidity $H M D$, wind speed $W S D$, and a dummy holidays $D H$. CDD is a temperature function, which is measure severity and duration of condition of hot days / summer [10]. To observe further effect of temperature, the values of one hour previous temperature $C D D(-1)$ are also included in model as in [10]. Next, the demand model is formulated as in Eq. (1).

$$
\begin{gathered}
\text { WPED }_{m}=\alpha_{0}+\alpha_{1} C D D+\alpha_{2} C D D(-1)+\alpha_{3} H M D \\
+\alpha_{4} W S D+\alpha_{5} D H+u_{t}
\end{gathered}
$$

where $W P E D_{m}$ is load demand for whole hour period. $\alpha_{0}$ is intercept value and other $\alpha$ values are regression coefficient. Meanwhile, $u_{t}$ is a term of residual. For $D H$, it has value 1 for holidays in model, and 0 otherwise. We use common method incorporating autoregressive in residual term of model to reduce autocorrelation in the composed model [11]. Here, we test and asses $W P E D_{m}$ model until autoregressive order three, and then use $A I C$ test (Akaike Information Criterion) and $S C$ (Schwarz Criterion) test to determine the best one among model options. To dealing with heteroskedasticity, corrected standard error regression is applied [11].

\section{2) Daytime maximum demand model (DMDm model)}

From basic data analysis, one of the maximum demand periods take place at daytime. It occurs mostly around 13.00 to 15.00 . Based on these hours, $D M D_{m}$ model is composed with intention to identify the characteristic of demand when electricity load is high. Concerning of the considered explanation variables in model, they are same as used in the $W P E D_{m}$ model with intention to observe main load drivers and their effect under certain demand period. Equation of the model is rewritten as follows.

$$
\begin{gathered}
D M D_{m}=\beta_{0}+\beta_{1} C D D+\beta_{2} C D D(-1)+\beta_{3} H M D \\
+\beta_{4} W S D+\beta_{5} D H+u_{t}
\end{gathered}
$$

where $D M D_{m}$ are load during daytime maximum demand period namely between 13.00 and 15.00 . Other variables in the above equation and applied statistical processes are similar with $W P E D_{m}$ model.

\section{RESUlts}

Regression results for best models are shown in Table I and Table II. The $W P E D_{m}$ model and $D M D_{m}$ model in the tables are specified with $3^{\text {rd }}$ order autoregressive and $1^{\text {st }}$ order autoregressive, respectively (their values are not shown). The best models is determined based on the smallest values of 
AIC and SC tests [10], and the highest value of their adjusted of coefficient determination $\left(R^{2,}\right)$. Both models have quite good fitness degree as their $R^{2}$, values are above $71 \%$. From obtained results, each model is well validated. Durbin-Watson (D-W) values are around 2, indicating the absence of autocorrelation in models. Prob. (F-Statistic) values are zero showing at least one of considered variables in related models influence whole demand $\left(\mathrm{WPED}_{\mathrm{m}}\right.$ model) and daytime maximum demand $\left(\mathrm{DMD}_{\mathrm{m}}\right.$ model).

TABLE I: RESULTS FOR BEST WPED ${ }_{M}$ MODEL (EQ. 1)

\begin{tabular}{|c|c|c|}
\hline \multirow{2}{*}{ Expl. Variable } & \multicolumn{2}{|c|}{ WPED $_{\mathrm{m}}$ Model } \\
\hline & Coef. & Prob. (p-value) \\
\hline \multirow[b]{2}{*}{$\alpha_{0}$} & 5.5321 & 0.0148 \\
\hline & $2.2682^{\mathrm{a}}$ & $2.4389^{b}$ \\
\hline \multirow{2}{*}{ CDD } & 0.6886 & 0.0000 \\
\hline & $0.1202^{\mathrm{a}}$ & $5.7262^{b}$ \\
\hline \multirow{2}{*}{$\operatorname{CDD}(-1)$} & 0.1342 & 0.1704 \\
\hline & $0.0978^{\mathrm{a}}$ & $1.3715^{\mathrm{b}}$ \\
\hline \multirow{2}{*}{ HMD } & 0.1067 & 0.0000 \\
\hline & $0.0219^{a}$ & $4.8670^{\mathrm{b}}$ \\
\hline \multirow{2}{*}{ WSD } & -0.1073 & $\underline{0.3356}$ \\
\hline & $0.1114^{\mathrm{a}}$ & $-0.9633^{b}$ \\
\hline \multirow{2}{*}{$\mathrm{DH}$} & -0.9073 & 0.0007 \\
\hline & $0.2679^{a}$ & $-3.3858^{b}$ \\
\hline$R^{2}$ & \multicolumn{2}{|c|}{0.7171} \\
\hline SE Reg. & \multicolumn{2}{|c|}{1.6780} \\
\hline Prob. F-Stat. & \multicolumn{2}{|c|}{0.0000} \\
\hline AIC & \multicolumn{2}{|c|}{3.8792} \\
\hline SC & \multicolumn{2}{|c|}{3.9118} \\
\hline D-W & \multicolumn{2}{|c|}{1.9765} \\
\hline
\end{tabular}

Notes: ${ }^{a}$ adjs. standard error, ${ }^{\mathrm{b}}$ t-statistic, _is not significant, $R^{2}$, without $\mathrm{CDD}(-1)$ and $\mathrm{WSD}$ in $\mathrm{WPED}_{\mathrm{m}}$ model is $71.61 \%$.

TABLE II: RESUltS FOR BEST DMD $D_{M}$ MOdeL (EQ. 2)

\begin{tabular}{|c|c|c|}
\hline \multirow{2}{*}{ Expl. Variable } & \multicolumn{2}{|c|}{ DMD $_{\mathrm{m}}$ Model } \\
\hline & Coef. & Prob. (p-value) \\
\hline \multirow[b]{2}{*}{$\beta_{0}$} & 15.4181 & 0.0000 \\
\hline & $3.2938^{\mathrm{a}}$ & $4.6809^{b}$ \\
\hline \multirow{2}{*}{ CDD } & 0.3333 & 0.0070 \\
\hline & $0.1221^{a}$ & $2.7282^{b}$ \\
\hline \multirow{2}{*}{$\operatorname{CDD}(-1)$} & 0.1267 & 0.0536 \\
\hline & $0.0652^{\mathrm{a}}$ & $1.9434^{\mathrm{b}}$ \\
\hline \multirow{2}{*}{ HMD } & 0.0433 & 0.0752 \\
\hline & $0.0242^{\mathrm{a}}$ & $1.7899^{b}$ \\
\hline \multirow{2}{*}{ WSD } & -0.0315 & $\underline{0.8382}$ \\
\hline & $0.1541^{\mathrm{a}}$ & $-0.2044^{b}$ \\
\hline \multirow{2}{*}{ DH } & -3.4496 & 0.0000 \\
\hline & $0.2998^{\mathrm{a}}$ & $-11.5050^{b}$ \\
\hline$R^{2 \prime}$ & \multicolumn{2}{|c|}{0.7568} \\
\hline SE Reg. & \multicolumn{2}{|c|}{1.1017} \\
\hline Prob. F-Stat. & \multicolumn{2}{|c|}{0.0000} \\
\hline AIC & \multicolumn{2}{|c|}{3.0695} \\
\hline SC & \multicolumn{2}{|c|}{3.1932} \\
\hline $\mathrm{D}-\mathrm{W}$ & \multicolumn{2}{|c|}{1.9796} \\
\hline
\end{tabular}

Notes: ${ }^{\mathrm{a}}$ adjs. standard error, ${ }^{\mathrm{b}}$ t-statistic, _is not significant, $R^{2}$ ' without WSD in $\mathrm{DMD}_{\mathrm{m}}$ model is $75.81 \%$.

\section{A. Results for WPED $D_{m}$ Model}

By using $10 \%$ significance level of p-value in this case, $C D D(-1)$ and $W S D$ variables have no significance in influencing demand as their $p$-values are above 0.1. For simplification, elimination of non-significance variables in $W P E D_{m}$ model can be done without affect much regression results. $C D D$ variable has the highest effect on demand (0.6886) and followed by HMD (0.1067). Meanwhile for holidays variable (DH), it has significance effect in reducing demand as shown by its regression coefficient (-0.9073). In holidays, many electrical devices are usually off such as in office and it contributes to the result.

\section{B. Results for $D M D_{m}$ Model}

Applying the same significance level as in $W P E D_{m}$ model, it is found only WSD variable has no significance in $D M D_{m}$ model. As wind speed values are relatively low (mean wind speed around $0.66 \mathrm{~m} / \mathrm{sec}$ ), this contributes to non-significance of the WSD variable in all models. Both temperature functions $C D D$ and $C D D(-1)$ have influence on daytime maximum demand hours with regression coefficients about 0.3333 and 0.1267 , respectively. The high temperature values in this period $(13.00-15.00)$ with mean values around $32.26{ }^{\circ} \mathrm{C}$ may relate to the significance effect including previous one hour temperature $C D D(-1)$ to the daytime maximum demand. Meanwhile humidity $H M D$ gives lowest effect on demand among significance meteorological variables. For holidays (DH), it will make related demand lower.

\section{Characteristic Comparison between Demand Period}

Comparing between models, $R^{2}$, values is slightly higher for $D M D_{m}$ model (75.68\%) than for $W P E D_{m}$ model (71.71\%). It means variables can explain better load during daytime maximum demand period than for whole demand period. Base demand during maximum demand period is higher. It is indicated by intercept value $\beta_{0}(15.4181)$ is larger than $\alpha_{0}$ value (5.5321). For meteorological parameters, they have larger effect in influencing whole demand period than maximum demand period as shown by their regression coefficients excluding $C D D(-1)$ which is not significant in $W P E D_{m}$ model. For holidays (DH), it will reduce much daytime maximum demand as in this period electrical devices are intensively used following high activities of human in Makassar such as at working places.

\section{CONCLUSIONS}

We use regression analysis in developing demand models $\left(\mathrm{WPED}_{\mathrm{m}}\right.$ model and $\mathrm{DMD}_{\mathrm{m}}$ model) to observe typical characteristics of demand in Makassar - Indonesia for whole period of demand and for daytime maximum demand period by using same explanation variables, namely meteorological parameters and holidays. Results confirm demand models for related period are well validated. All models have quite good fitness degree as their $R^{2}$, values exceed $71 \%$. Load drivers and their effect on the observed demand periods are found different. Among meteorological parameters, temperature functions show important role mainly on daytime maximum demand period in terms of both $C D D$ and $C D D(-1)$ have significance in $D M D_{m}$ model. Holidays reduce demand mainly for daytime maximum demand hours. Presented information can be utilized for purpose of managing power system operation more effective particularly during daytime maximum demand period to keep continuity service to connected load under tropical environment.

\section{ACKNOWLEDGMENT}

We would like to express our thanks to PT. PLN (Persero) Area Pengatur Distribusi Makassar, Pusat Sains dan Teknologi Atmosfer - LAPAN, and The Indonesian Central Bureau of Statistics (BPS) - Sulawesi Selatan Province for providing data in this work, and Mr. A. A. H. Lateko for 
assisting in data collection in Makassar

\section{REFERENCES}

[1] S. B. Sadineni and R. F. Boehm, "Measurements and simulations for peak electrical load reduction in cooling dominated climate," Energy, vol. 37, pp. 689-697, 2012.

[2] D. H. W. Li, J. C. Lam, and S. L. Wong, "Daylighting and its effects on peak load determination,” Energy, vol. 30, pp. 1817-1831, 2005.

[3] I. S. Qamber, "Peak load modeling for Kingdom of Bahrain,” Journal of Software Engineering and Applications, vol. 5, no. 12B, pp. 46-49, 2012.

[4] M. A. Almeida, R. Schaeffer, and E. L. L. Rovere, "The potential for electricity conservation and peak load reduction in the residential sector of Brazil,” Energy, vol. 26, pp. 413-429, 2001.

[5] S. Dudhani, A. K. Sinha, and S. S. Inamdar, "Renewable energy sources for peak load demand management in India," Electrical Power and Energy Systems, vol. 28, pp. 396-400, 2006.

[6] Y. S. Akil, Syafaruddin, T. Waris, and A. A. H. Lateko, "The influence of meteorological parameters under tropical condition on electricity demand characteristic: Indonesia case study," in Proc. the $1^{\text {st }}$ International Conference on Information Technology, Computer, and Electrical Engineering, pp. 381-385, 2014.

[7] Y. S. Akil and H. Miyauchi, "Seasonal peak electricity demand characteristics: Japan case study," International Journal of Energy and Power Engineering, vol. 2, no. 3, pp. 136-142, 2013.

[8] Y. S. Akil and H. Miyauchi, "Seasonal peak characteristic comparison analysis by hourly electricity demand model," International Journal of Energy and Power Engineering, vol. 3, no. 3, pp. 132-138, 2014.

[9] BPS - Statistics Sulawesi Selatan Province, Sulawesi Selatan in Figures 2010-2012.

[10] A. Pardo, V. Meneu, and E. Valor, "Temperature and seasonality influences on Spanish electricity load,” Energy Economics, vol. 24, pp. 55-70, 2002.

[11] R. Startz, EViews Illustrated for Version 6, 1st ed., Quantitative Micro Software, LLC, 2007.

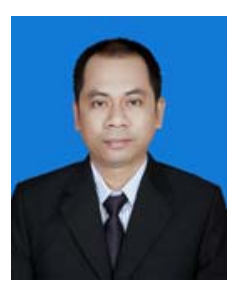

Yusri Syam Akil obtained his B.Eng in electrical engineering from Hasanuddin University, Indonesia in 2001. In 2005, he obtained his master in electrical engineering from the same university. Next, in 2013 he obtained his Ph.D in computer science and electrical engineering from Kumamoto University, Japan. He is a lecturer and a researcher at Electrical Engineering Department, Faculty of Engineering,
Hasanuddin University, Indonesia. His research interests are in the power demand analysis and forecasting, renewable energy, and power system optimization.

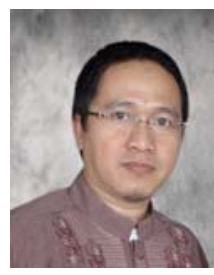

Syafaruddin received his B.Eng degree in electrical engineering from Universitas Hasanuddin, Indonesia, in 1996, M.Eng degree in electrical engineering from University of Queensland, Australia, in 2004 and D.Eng degree from Kumamoto University, Japan in 2009. He has been working in Kumamoto University for two years as a project assistant professor for Graduate School of Science and Technology, sponsored by Endowed Chair of Kumamoto University. His current position is a senior lecturer in Department of Electrical Engineering Universitas Hasanuddin, Indonesia. His research interests include renewable energy integration and optimization, maximum power point tracking control of photovoltaic system, real-time system and intelligent system applications to power system.

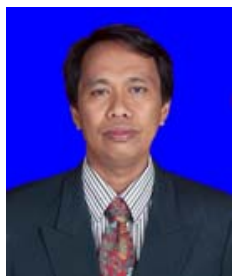

Tajuddin Waris holds B.E and M.E in electrical power engineering from Hasanuddin University. Currently, he served as a lecturer on the Electrical Engineering Departement of Hasanuddin University, Indonesia. His research interest and publication are in renewable energy and power drive to variable speed diesel power generation.

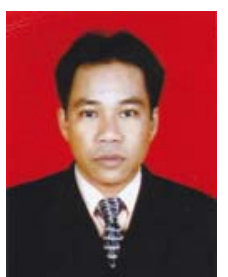

Imran Taufik was born in Sengkang, Indonesia. He obtained his B.Eng in electrical power engineering from Universitas Muslim Indonesia, Indonesia in 1999. In 2006, he obtained his master in resource economics from Hasanuddin University, Indonesia. He is pursuing his doctoral program in economics at Hasanuddin University. Currently, he is the head of Department of Information System in STMIK Handayani Makassar, Indonesia. Besides economics, his research interests include field of electricity, and information management and computer. 